\title{
Integrated Magnetics, Insulation and Cooling Architecture for Slotless Electric Machines
}

This paper was downloaded from TechRxiv (https://www.techrxiv.org).

\section{LICENSE}

CC BY 4.0

SUBMISSION DATE / POSTED DATE

$30-10-2021 / 01-11-2021$

\section{CITATION}

Lee, Dongsu (2021): Integrated Magnetics, Insulation and Cooling Architecture for Slotless Electric Machines. TechRxiv. Preprint. https://doi.org/10.36227/techrxiv.16909213.v1

$\mathrm{DOI}$

10.36227/techrxiv.16909213.v1 


\title{
Integrated Magnetics, Insulation and Cooling Architecture for Slotless Electric Machines
}

\author{
${ }^{1}$ Dongsu Lee, ${ }^{1}$ Noah Salk, ${ }^{1}$ Thanatheepan Balachandran, ${ }^{1}$ Paige Powell, ${ }^{1}$ Kiruba Haran, Fellow, IEEE \\ ${ }^{1}$ Hinetics LLC, Champaign, IL, 61820, USA
}

\begin{abstract}
This paper proposes an integrated magnetics, insulation, and cooling architecture to improve the thermal performance of a high frequency permanent magnet (PM) motor. The proposed architecture can be used for any motor topology to improve its thermal and insulation performance. The proposed stator yoke design interleaves copper sheets between yoke core lamination to achieve better thermal conduction from winding to heat sink. A ceramic winding holder is integrated into the armature to introduce a parallel thermal conduction path from windings to the iron yoke and to provide additional insulation. The architecture is applied to a $300 \mathrm{~kW}$ slotless PM synchronous motor consisting of an outer rotor Halbach PM array, slotless stator, and heatsink. 3D electromagnetic finite element methods (FEM), 2D heat transfer FEM, and an analytical thermal circuit are used to analyze the architectures impact on torque production, eddy currents, and thermal performance when compared to the baseline motor. Finally, a pole-pair prototype was built as a proof-of-concept and to verify the performance benefits of the proposed architecture.
\end{abstract}

Index Terms - Ceramic winding insulation, cooling architecture, interleaved copper sheets, permanent magnet motor

\section{INTRODUCTION}

$\mathrm{E}^{\mathrm{s}}$ LECTRIC vertical takeoff and landing (eVTOL) aircraft require compact, high power, high reliability electric motors and drives. Power demand on the electric aircraft propulsion (EAP) system during take-off and landing can be up to 3-10x cruise power [1,2], and copper loss during these flight phases rises due to increased current density. As a result, the temperature in the conducting region can grow quickly to levels that threaten insulation failure. This paper presents an embedded cooling architecture that enhances heat transfer from the coils to the heatsink and prevents excessive temperatures [3]. The proposed machine topology is a slotless permanent magnet synchronous machine (PMSM) outrunner which achieves high electrical loading by extending the armature cross-section into area traditionally occupied by iron teeth [4,5], making it suitable for the operating profiles of eVTOL aircraft [6]. The slotless structure trades-off magnetic loading and associated iron loss for electrical loading and associated copper loss.

Two critical features of the proposed integrated magnetics, insulation, and cooling architecture (MAGICA) are:

a) To address the high loss concentration in the formwound coils of a slotless stator, thin copper sheets are interleaved within the iron lamination stack to provide a thermal shunt from coils to heatsink.

b) Implement a ceramic coil holder which enhances both the side-wall thermal path and electrical insulation [7].

Several simulations were performed with a $3 \mathrm{D}$ finite element analysis (FEA) and a lumped element thermal equivalent circuit to confirm the modified motor's performance. The former is for obtaining electromagnetic performance including torque production, iron loss, and eddy current loss according to interleaved copper sheet thickness [8]. The latter is for estimating the thermal impact of the interleaved copper/iron yoke and ceramic holder. The combined performance is compared with a baseline motor with conventional iron core laminations and no coil holder [9]. Finally, a prototype is built and experimentally tested to demonstrate qualitative performance improvements. Results show the proposed architecture is feasible to construct, suitable for electric aircraft propulsion, and provides significant thermal performance benefits.

Section II introduces the MAGICA concept and thermal equivalent circuit. Section III presents the results from 3D electromagnetic FEA studies. Section IV and V provides preliminary experimental test results and a conclusion.

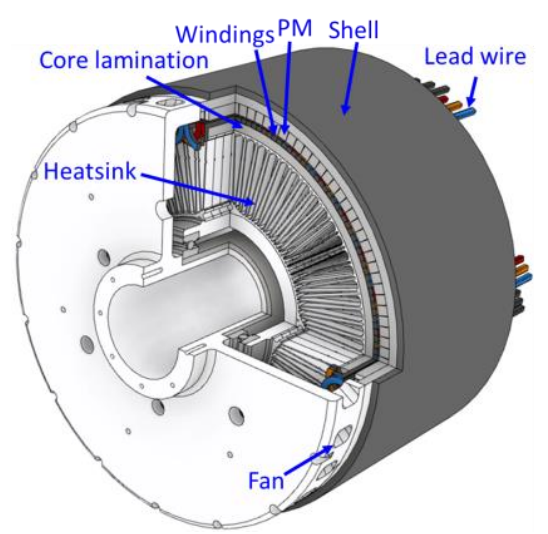

Fig 1. Configuration of a slotless PMSM

Table 1. Design specifications of a target slotless PMSM

\begin{tabular}{c|c|c|c}
\hline \hline \multicolumn{2}{c|}{ Specification } & Value & Unit \\
\hline \hline \multirow{3}{*}{ Performance } & Power & 300 & $\mathrm{~kW}$ \\
\cline { 2 - 4 } & Torque & 796 & $\mathrm{~N}-\mathrm{m}$ \\
\cline { 2 - 4 } & Speed & 3,600 & $\mathrm{rpm}$ \\
\hline \multirow{2}{*}{ Material } & PM & $\mathrm{N} 45 \mathrm{UH}$ & - \\
\cline { 2 - 4 } & Core & $\mathrm{HF}-10$ & - \\
\hline \multirow{2}{*}{ Size } & OD & 377 & $\mathrm{~mm}$ \\
\cline { 2 - 4 } & Axial & 241 & $\mathrm{~mm}$ \\
\hline \hline
\end{tabular}

Corresponding author: Dongsu Lee (e-mail: dlee@hinetics.com).

Digital Object Identifier (inserted by IEEE). 


\section{THE PROPOSED INTEGRATED MAGNETICS, INSULATION AND COOLING ARCHITECTURE (MAGICA)}

\section{A. Slotless PMSM Specification}

A $300 \mathrm{~kW}$ slotless PMSM is designed with and without the proposed MAGIA to demonstrate the performance characteristics of the motor. The proposed motor consists of an outer rotor Halbach PM array, shell, core lamination, heatsink, slotless 3 phase armature structure. The machine configuration and specifications are shown in Fig. 1 and Table I.

\section{B. Cooling Architecture}

Thermal limits [10] and electrical insulation [11] are the two critical reliability concerns identified in these motors for EAP applications. Fig. 2 (a) shows a 2-D cross-section of the current slotless stator cooling architecture as implemented in both a 1MW machine [12] and a 300-kW machine [13]. In comparison, Fig. 2 (b) shows a 2-D cross-section of the proposed MAGICA topology which improves the thermal and dielectric performance of the baseline motor, making it more robust and torque dense. MAGICA consists of three independent thermal improvements, each lowering separate elements in the series thermal impedance from winding to coolant. The first layer consists of a ceramic coil holder in which the form-wound Litz conductors are placed. This coil holder introduces an additional side-wall parallel heat path from the windings to the heat sink. Furthermore, the ceramic improves line-to-ground and line-toline insulation, reducing the risk of insulation failure and partial discharge activity. The second layer is a yoke composed of interleaved iron and copper lamination. High thermal conductivity thin copper sheets are periodically inserted within the lamination stack to thermally shunt the flux-supporting magnetic iron and its relatively poor thermal properties. A third layer consists of an additively manufactured heat sink which improves air-side heat transfer over the baseline radial fin heat sink through increased surface area.

\section{Thermal Equivalent Circuit Model}

Fig. 3 (a) shows a simplified lumped thermal circuit model of the current machine's heat path and Fig. 3 (b) shows a simplified lumped circuit model of the heat path in MAGICA. Parallel thermal paths are marked on the lumped circuit model to demonstrate the significant benefits of the proposed topology. The remainder of this paper will discuss in detail only the first two improvements of MAGICA, future work will focus on the design and optimization of an improved, axially-varying heat sink. Given the material properties tabulated in Table II, the thermal resistance of each lumped element can be calculated from the stator dimensions,

$$
R_{t h}=\frac{l}{k A}
$$

where, $k$ is the thermal resistivity of the material, $l$ is the length of the material layer, and $A$ is the area of the layer. First order calculations were made based on the dimensions of a $300 \mathrm{~kW}$ machine, assuming conservative ceramic dimensions and $10 \%$ copper sheet fill in the lamination stack. A comparison between individual lumped thermal elements in the baseline topology

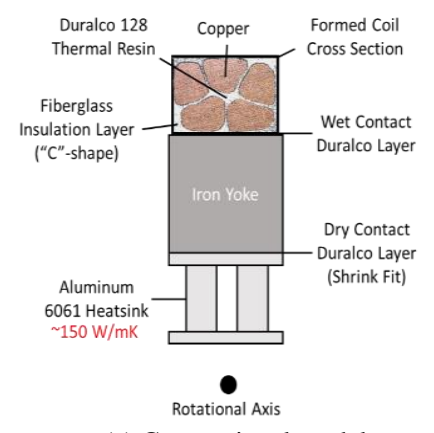

(a) Conventional model

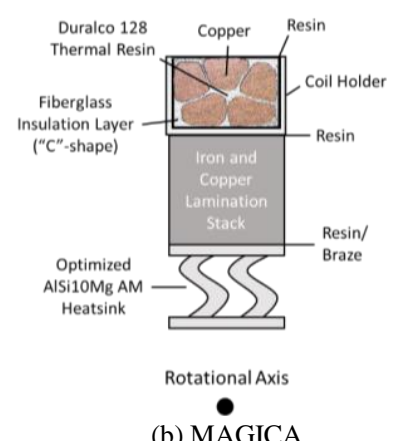

(b) MAGICA
Fig 2. 2-D cross-section view of cooling architecture

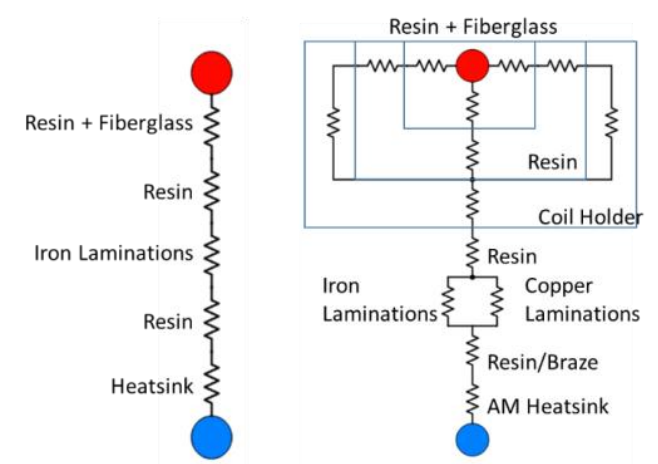

$\begin{array}{ll}\text { (a) Baseline model } & \text { (b) MAGICA }\end{array}$

Fig. 3. Lumped thermal circuit model

Table II. Material thermal properties

\begin{tabular}{c|c}
\hline \hline Material & Thermal conductivity [W/m-K] \\
\hline \hline Resin & 2.88 \\
\hline Fiber glass cloth & 0.1 \\
\hline AIN ceramic & 92 \\
\hline Iron lamination & 30 \\
\hline Copper lamination & 350 \\
\hline AM AlSi10Mg & 50 \\
\hline \hline
\end{tabular}

Table III. Comparison of lumped element thermal impedances in the baseline machine and in MAGICA (not including heat sink)

\begin{tabular}{l|c|c}
\hline \hline \multicolumn{1}{c|}{ Thermal path } & $\begin{array}{c}\text { Conventional } \\
{[\mathrm{K} / \mathrm{W}]}\end{array}$ & $\begin{array}{c}\text { MAGICA } \\
{[\mathrm{K} / \mathrm{W}]}\end{array}$ \\
\hline \hline Resin + fiber (ground wall) - radial & 0.101 & 0.101 \\
\hline $\begin{array}{l}\text { Resin winding to yoke/ceramic holder } \\
\text { (ground wall) - radial }\end{array}$ & 0.026 & 0.026 \\
\hline Ceramic (ground wall) - radial & N/A (0) & 0.012 \\
\hline $\begin{array}{l}\text { Resin ceramic holder to yoke (ground } \\
\text { wall) - radial }\end{array}$ & N/A (0) & 0.026 \\
\hline Yoke/ infused yoke (ground wall) - radial & 0.201 & 0.097 \\
\hline $\begin{array}{l}\text { Resin Yoke to heat sink (ground wall) - } \\
\text { radial }\end{array}$ & 0.026 & 0.026 \\
\hline Resin (side wall) - peripheral & 0.006 & 0.006 \\
\hline Resin + fiber (side wall) - peripheral & 0.069 & 0.069 \\
\hline Ceramic (side wall) - peripheral & N/A (0) & 0.005 \\
\hline Ceramic (side wall) - radial & N/A ( $\infty)$ & 0.006 \\
\hline Equivalent Thermal Resistance & 0.354 & 0.214 \\
\hline \hline
\end{tabular}

and MAGICA is tabulated in Table III to demonstrate the potential thermal improvements possible with the new cooling architecture.

\section{Ceramic Holder Performance}

Two material candidates for the ceramic coil holder were identified; both Aluminum Nitride (AlN) and Boron Nitride 


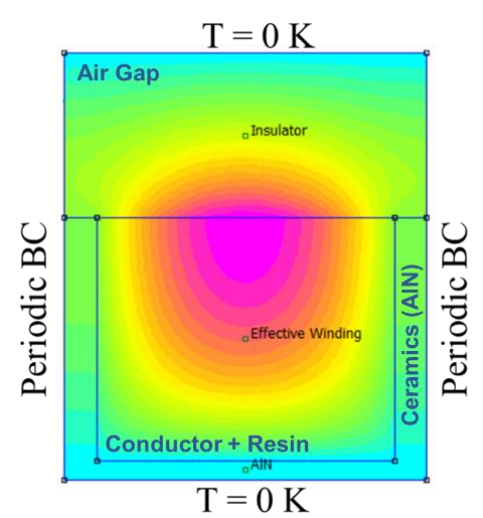

Fig. 4. Coil holder slot thermal study FEM setup

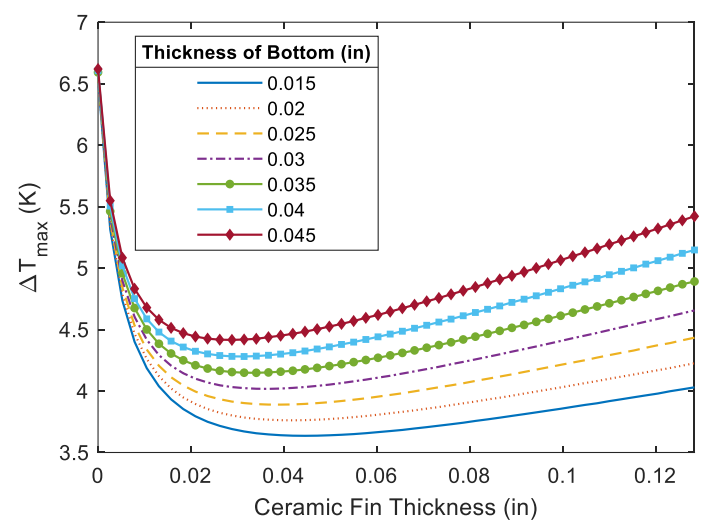

Fig. 5. Max temperatures rise versus ceramic fin thickness

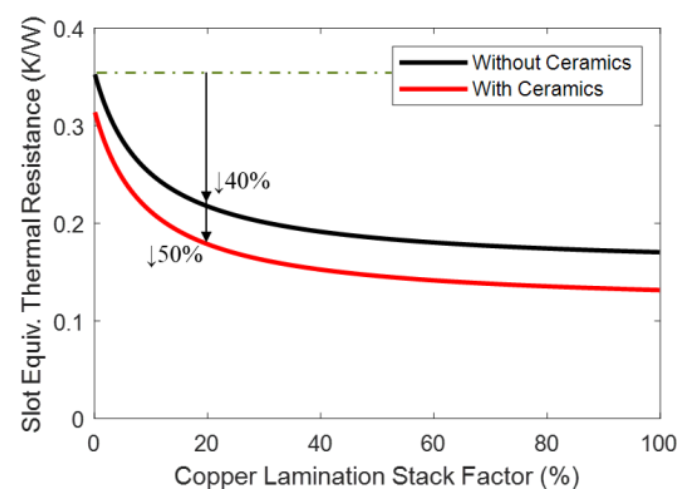

Fig. 6. Equivalent thermal resistance of the slot from winding to heatsink, with and without the use of ceramics

(BN) are machinable and have attractive thermal, electrical, and structural properties. The remainder of this paper will utilize the relatively less mature and more expensive AlN material, which promises better performance across the board when compared to BN. Choosing the dimensions of the coil holder is non-trivial due to the ' $\mathrm{C}$ '-shaped geometry. In general, the ceramic thickness at the base of the coil holder should be made as thin as possible to minimize its purely series thermal impedance and adverse consequences on EM performance from an increased airgap. However, there exist an optimal thickness of the coil holder fins (between conductors); too thick of ceramic fins reduces the available conduction area, increasing the current and loss density. Conversely, too thin of ceramic fins nullifies the parallel thermal path. An additional constraint is that there exists a lower limit for the machinable thickness of the ceramic material. A steady-state thermal FEA study was carried out in the open-source FEMM software to determine the optimal fin thickness for a given base thickness by minimizing $\Delta T_{\max }$. The simulation setup is shown in Fig. 4 and only concerns the ceramic and conductor region. Heat is forced to dissipate through the base of the heatsink by including an insulating airgap. The results of the study are plotted in Fig. 5 for several base thicknesses and are used later in this paper when combined with results from ceramic test cuts to determine the final coil holder dimensions.

\section{E. Lamination Stack Copper Fill Thermal Analysis}

In order to observe the potential benefit obtained through introducing interleaved copper sheets in the lamination stack, the lumped element thermal circuit in Fig. 3 (b) was used to produce the equivalent thermal resistance per slot from the center of the windings to the outer surface of the heatsink as a function of the copper fill percentage. Using the numbers given in Table II, two curves are generated and shown in Fig. 6: one including the ceramic coil holder and one only including the interleaved copper laminations. The dashed horizontal line denotes the baseline thermal resistance, corresponding to $0 \%$ copper fill and no ceramics. Just by including interleaved copper sheets into the yoke stack, the equivalent thermal resistance from conductor to heatsink is reduced by $40 \%$ at just $20 \%$ copper fill. Including ceramics in the analysis, an additional $10 \%$ reduction in equivalent thermal resistance is observed. A saturation of the benefits is also observed at larger copper fills due to the form-wound Litz conductors becoming the thermal bottleneck. The next section will discuss the impact of copper fill on the motor's electromagnetic performance.

\section{Electromagnetic Performance}

Section II showed that MAGICA improves the machine's thermal and performance. This section is focused on electromagnetic analysis when the architecture is applied to the $300 \mathrm{~kW}$ machine in order to understand the impact on electrical performance. A 3D FEA analysis is performed to analyze the added feature's impact on flux density distribution, eddy current losses, and torque production in the machine.

\section{A. Flux Density}

The axially varying interleaved copper and iron yoke laminations necessitate a 3D analysis due to non-zero axial flux components. A one pole section of the motor with half the designed stack length is modeled in this study. The machine prototype is designed and built with 0.01 " thick HF-10 core laminations. However, to save memory while studying the high-level electromagnetic phenomena of core saturation and torque production, the machine is modeled with 100 laminations, each at $1.2065 \mathrm{~mm}$ thick. Iron and copper laminations set to the same thickness. Fig. 7 shows the lamination stack's flux density distribution with varying copper lamination stacking factors. A yoke design at $0 \%$ copper stack factor (no copper) resulted in a peak flux density of 1.05 1.1 


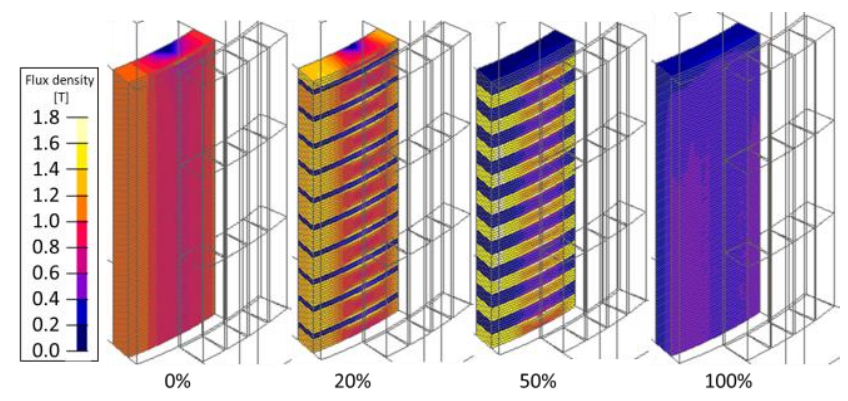

(a) Flux density in all regions with varying copper stacking factors. Flux carrying regions are iron laminations, and non-flux carrying regions are copper laminations.

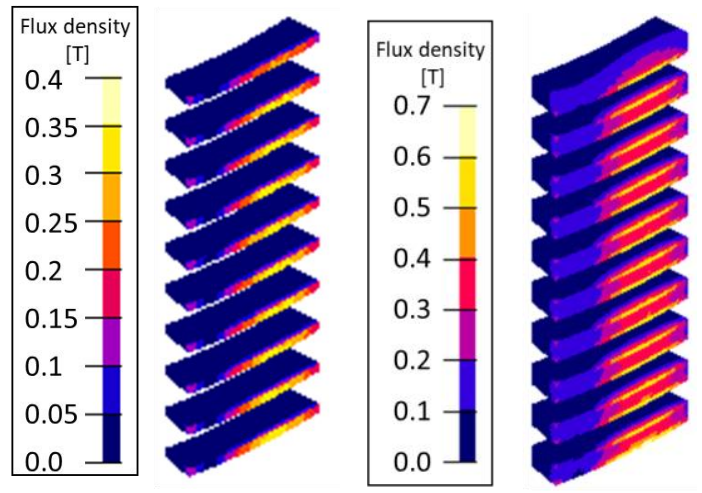

(b) Flux density distribution in the copper lamination region alone Fig 7. Flux density distribution in the MAGICA yoke

$\mathrm{T}$, while a $100 \%$ copper stack factor design (all copper) gave a peak flux density of $0.4 \mathrm{~T}$, similar to an air-core design. Spatial core saturation becomes more severe with increasing copper stacking factors. As shown in Fig. 7 (b), the highest flux densities seen by the copper laminations are at the air-gap side edges, suggesting fringing effects. This suggests that significant eddy current losses may be generated in the copper laminations.

\section{B. Impact on Torque Production}

Fig. 8 shows the variation of torque production according to the copper lamination stack factor. The torque computed at $0 \%$ and 100\% copper stacking factors are $790 \mathrm{Nm}$ and $473 \mathrm{Nm}$ respectively. It is evident from this analysis that if the copper lamination stacking factor is maintained below $20 \%$, the impact on the torque performance is insignificant. A drop-off in torque production happens after 20 30\% copper stacking factor due to saturated steel laminations in the yoke.

\section{Iron Loss}

Due to the higher electrical loading in slotless machines, copper loss generally dominates iron losses. Copper losses and iron losses are evaluated using a 2D FEA simulation and Steinmetz models [14]. The machine designed without MAGICA has $6,893 \mathrm{~W}$ of copper losses and $667 \mathrm{~W}$ of iron losses at the rated operating condition. In this case, the machine core air-gap flux density was evaluated to be $1.06 \mathrm{~T}$. As shown in Fig. 9, when integrated with MAGICA at 20\% copper stacking factor, the peak flux density increases to $1.3 \mathrm{~T}$, resulting in an increase in iron losses to $1,095 \mathrm{~W}$.

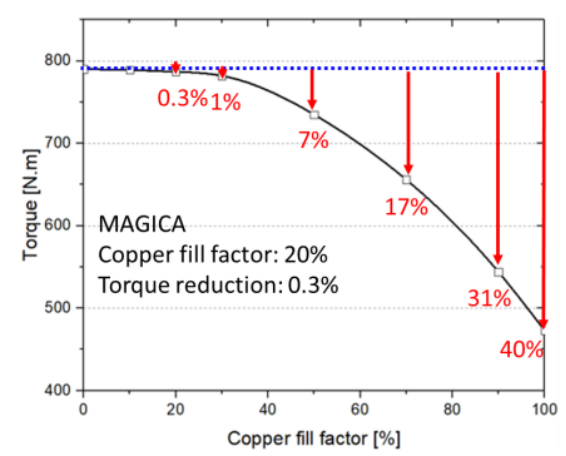

Fig 8. Torque production vs. copper stacking factor

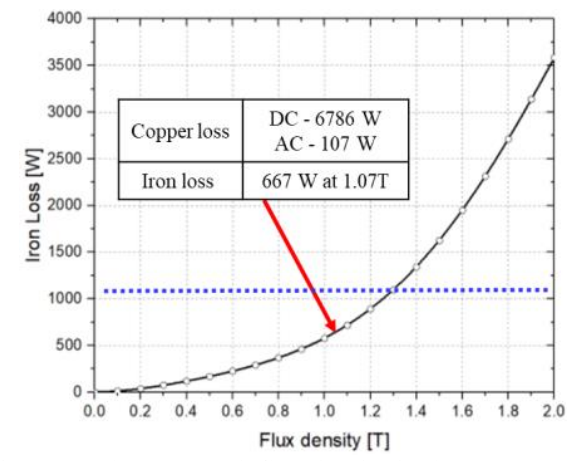

Fig 9. Iron loss vs. peak flux density in the HF-10 material

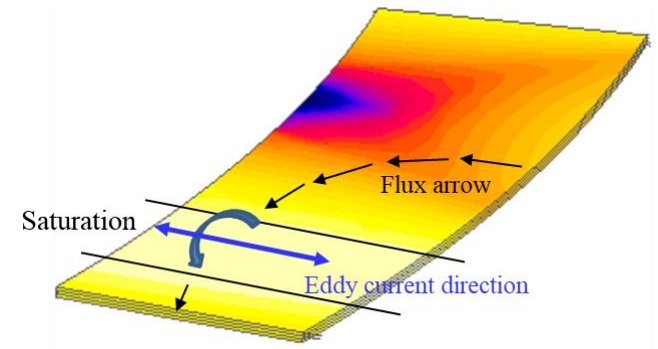

Fig 10. Flux density and eddy current direction in the core lamination

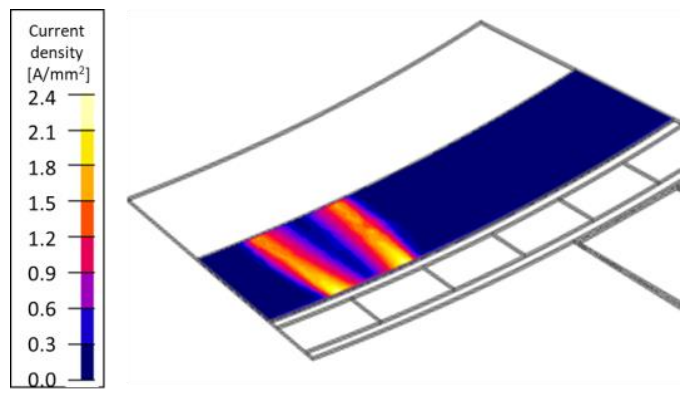

Fig 11. Eddy current loss density in $33.3 \%$ copper fill factor.

\section{Eddy Current loss}

The air-gap side edges of the iron laminations experience saturation due to fringing effects at the copper and iron interface. This leads to higher eddy current losses in the yoke and thus an increase in the yoke temperature. To study eddy currents at the lamination level, a 3D FEA model was setup with an iron lamination thickness of 0.01 " and copper lamination thickness of 0.005 " [15-17]. Eddy currents were evaluated by modeling one of each lamination, corresponding to a $33 \%$ copper stacking 
factor design. In radial flux motors significant eddy currents are generated in the axial direction of the core due to the radial flux lines between the rotor and stator. However, due to the fringing effect in the proposed design, flux can leak into the copper sheet as shown Fig. 10, thus generating eddy currents with a non-zero radial component. This is exaggerated near points of saturation.

Due to this fringing impact, the peak eddy current density for the $16.6 \%$ copper lamination fill factor was evaluated to be 0.7 $\mathrm{A}_{\mathrm{rms}} / \mathrm{mm}^{2}$ and $2.3 \mathrm{~A}_{\mathrm{rms}} / \mathrm{mm}^{2}$ for a $33.3 \%$ copper stacking factor as shown in Fig. 11. These values are much smaller than the traditional current density limits of ( $17 \mathrm{~A}_{\mathrm{rms}} / \mathrm{mm}^{2}$ per copper). The total eddy current losses in the core are negligible compared to the iron losses: $0.1 \mathrm{~W}$ at $20.0 \%$ copper stacking factor and $2.0 \mathrm{~W}$ at $33.3 \%$ copper stacking factor. Therefore, a $20 \%$ copper lamination stack factor was chosen for prototype development as it does not generate significant eddy current loss or a significant reduction in torque production.

\section{PRototype DEVELOPMENT \& PRELIMINARY EXPERIMENTAL RESULTS}

Through discussions with experienced machinists, it was determined that the best method of manufacturing the coil holder's complex geometry was by waterjet cutting the crosssectional profile from ceramic plates and stacking several of these segments axially to meet the active length of the machine. Waterjet cutting has minimal vibration and therefore presents the lowest risk of crack growth. The relatively higher in-plane than through-plane thermal conductivity of AlN means this method also maximizes the material performance. The thickest available AlN material $(7 \mathrm{~mm})$ was sourced to minimize the number of machining operations. Several test arrays with varying fin thicknesses were cut to calibrate the waterjet and determine minimum achievable dimensions. A minimum successful fin thickness of 0.015 " was achieved with no significant taper using a non-articulated waterjet head. However, final fin and base thicknesses of 0.030 " were chosen in consideration of thermal trade-offs discussed in Section III.C and to provide structural margin. The full pole-pair prototype of the ceramic coil holder is shown in Fig. 12.

A $4.5^{\prime \prime}$ long, $42.5^{\circ}$ pole-pair prototype of the MAGICA yoke was built to demonstrate thermal performance improvements. To compare with the baseline machine, 0.010 " thick HF-10 C5 insulated iron laminations were used. The copper laminations were made from 0.005 " thick Copper 110 alloy foil that was folded, compressed, and cut to the correct geometry via wire EDM. To achieve $20 \%$ copper fill in the lamination stack, one copper lamination was periodically placed for every two HF-10 laminations. Both sets of laminations were coated with EB-548 bonding epoxy prior to curing, however, the copper laminations also required a surface preparation. The resulting bonded MAGICA yoke is shown in Fig. 13.

A control group of the baseline, pure iron yoke was also built for side-by-side thermal performance comparisons between the two lamination stacks. A simple experiment was constructed to create a qualitative comparison of the two yokes. The test setup shown in Fig. 14 (a) consists of the two samples, a ceramic heater, and a thermal camera to monitor the outer surface

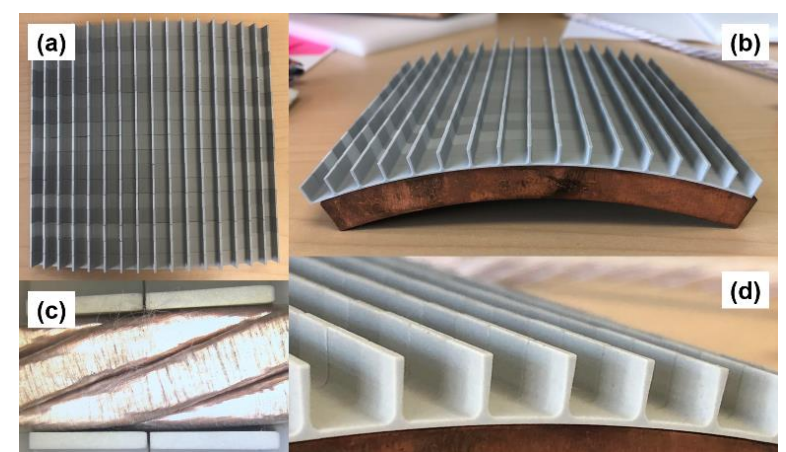

Fig 12. (a) full pole-pair prototype of the AlN coil holder (b) coil holder dry assembly onto interleaved copper-iron stack (b) dry assembly of one pre-formed Litz conductor in a coil holder slot (d) close-up of slot profile

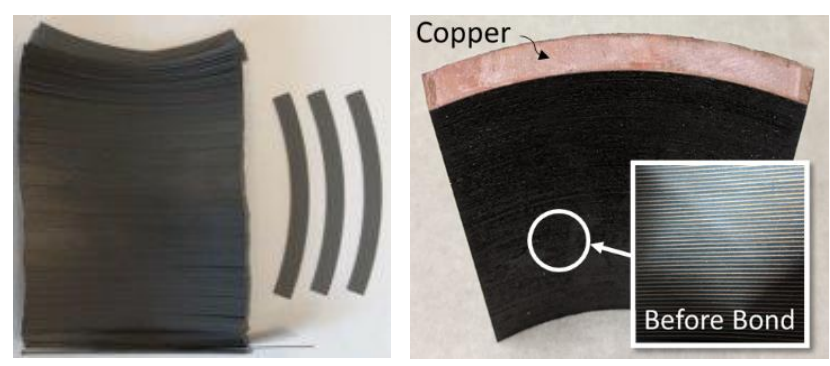

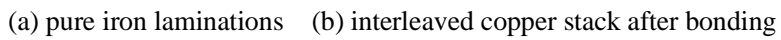
Fig. 13. Lamination stacks

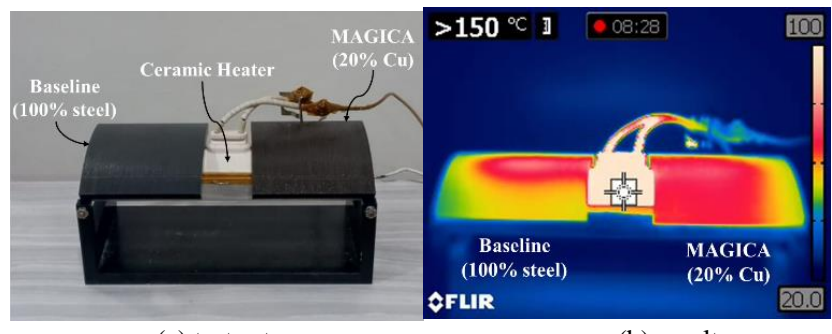

(a) test setup

(b) results

Fig. 14. Experimental test setup and thermal comparison

temperatures. The heat load was applied to the inner surface of each test article at $\mathrm{T}=0 \mathrm{~s}$. A snapshot of the results after roughly 8.5 minutes is shown in Fig. 14 (b). This preliminary experiment clearly demonstrated faster heat spread, more uniform temperature distribution, and lower hotspot temperatures in the MAGICA stack.

\section{CONCLUSIONS AND FUTURE WORK}

This paper proposed a novel integrated magnetics, insulation, and cooling architecture for improving thermal and insulation performance of electric motors. A $300 \mathrm{~kW}$ slotless PM motor is designed with and without MAGICA to illustrate the performance benefits gained with MAGICA. Analysis showed that an optimal copper stacking factor is $20 \%$ and that MAGICA can reduce the thermal impedance from windings to heatsink in the proposed motor by $50 \%$ with a maximum torque reduction of $1 \%$. The ceramic holder also provides additional insulation performance improvements with the potential to limit partial discharge (PD) activity. Future work will focus on further demonstration of MAGICA with hardware development, integration with an additively manufactured heatsink, and quantifying power density improvements and PD reduction. 


\section{REFERENCES}

[1] J. Xiao, N. Salk and K. Haran, "Conceptual Design of an eVTOL Air Shuttle for Rapid Intercity Transport," 2020 IEEE Power and Energy Conference at Illinois (PECI), 2020, pp. 1-8, doi: 10.1109/PECI48348.2020.9064631.

[2] M. S. Islam, R. Mikail and I. Husain, "Slotless Lightweight Motor for Aerial Applications," in IEEE Transactions on Industry Applications, vol. 55, no. 6, pp. 5789-5799, Nov.-Dec. 2019, doi: 10.1109/TIA.2019.2935055.

[3] Hyunkyu Moona, Nenad Miljkovic, William P. King, "High power density thermal energy storage using additively manufactured heat exchangers and phase change material", International Journal of Heat and Mass Transfer, 153, pp. 119591, 2020.

[4] D. Lee, A. Jin, B.-H. Min, L. Zheng, and K. Haran, "Optimisation method to maximise torque density of high-speed slotless permanent magnet synchronous machine in aerospace applications," IET Elect. Power Appl., vol. 12, no. 8, pp. 1075-1081, Aug. 2018.

[5] F. Luise et al., "Design Optimization and Testing of High-Performance Motors: Evaluating a Compromise Between Quality Design Development and Production Costs of a Halbach-Array PM Slotless Motor," in IEEE Industry Applications Magazine, vol. 22, no. 6, pp. 19-32, Nov.-Dec. 2016, doi: 10.1109/MIAS.2015.2459118.

[6] J. Harrison, D. Charles, J. Zenker and E. Frank, "Using Multi-physics System Simulation to Predict Battery Pack Thermal Performance and Risk of Thermal Runaway During eVTOL Aircraft Operations," 2019 AIAA/IEEE Electric Aircraft Technologies Symposium (EATS), 2019, pp. 1-13, doi: 10.2514/6.2019-4406.

[7] Z. Chen et al., "3D printing of ceramics: A review," Journal of the European Ceramic Society, vol. 39, pp. 661-687. 2019.

[8] J. Fang and S. Xu, "Effects of Eddy Current in Electrical Connection Surface of Laminated Cores on High-Speed PM Motor Supported by Active Magnetic Bearings," in IEEE Transactions on Magnetics, vol. 51, no. 11, pp. 1-4, Nov. 2015, Art no. 8207604.

[9] J. E. Cousineau, K. Bennion, D. DeVoto, and S. Narumanchi, "Experimental characterization and modeling of thermal resistance of electric machine lamination stacks," Int. J. Heat Mass Transf., vol. 129, pp. 152-159, Feb. 2019

[10] X. Yi and K. S. Haran, "Thermal Integration of a High-Frequency HighSpecific-Power Motor within Electrically Variable Engine," 2019 AIAA/IEEE Electric Aircraft Technologies Symposium (EATS), 2019, pp. 1-10, doi: 10.2514/6.2019-4405.

[11] T. Balachandran, S. Sirimmana, A. Jin and K. S. Haran, "Partial Discharge Testing of Form-Wound Air-Core Armature Windings for a HighFrequency PMSM for Electric Aircraft Applications," 2018 IEEE International Conference on Information and Automation for Sustainability (ICIAfS), 2018, pp. 1-6, doi: 10.1109/ICIAFS.2018.8913342.

[12] T. Balachandran, S. Srimmana, A. Anderson, X. Yi, N. Renner and K. S. Haran, "Assembly and Qualification of a Slotless Stator Assembly for a MW-Class Permanent Magnet Synchronous Machine," 2020 AIAA/IEEE Electric Aircraft Technologies Symposium (EATS), 2020, pp. 1-10.

[13] D. Lee et al., "Design and Prototype of a High Power Density Slotless PMSM for Direct Drive Aircraft Propulsion," 2021 IEEE Power and Energy Conference at Illinois (PECI), 2021, pp. 1-6, doi: 10.1109/PECI51586.2021.9435256.

[14] G. Novak, J. Kokošar, M. Bricelj, M. Bizjak, D. Steiner Petrovič and A. Nagode, "Improved Model Based on the Modified Steinmetz Equation for Predicting the Magnetic Losses in Non-Oriented Electrical Steels That is Valid for Elevated Temperatures and Frequencies," in IEEE Transactions on Magnetics, vol. 53, no. 10, pp. 1-5, Oct. 2017, Art no. 2001805.

[15] T. Okitsu, D. Matsuhashi and K. Muramatsu, "Method for Evaluating the Eddy Current Loss of a Permanent Magnet in a PM Motor Driven by an Inverter Power Supply Using Coupled 2-D and 3-D Finite Element Analyses," in IEEE Transactions on Magnetics, vol. 45, no. 10, pp. 45744577, Oct. 2009

[16] Y. Kawase, T. Ota and H. Fukunaga, "3-D eddy current analysis in permanent magnet of interior permanent magnet motors," in IEEE Transactions on Magnetics, vol. 36, no. 4, pp. 1863-1866, July 2000

[17] T. Okitsu, D. Matsuhashi, Y. Gao and K. Muramatsu, "Coupled 2-D and 3-D Eddy Current Analyses for Evaluating Eddy Current Loss of a Permanent Magnet in Surface PM Motors," in IEEE Transactions on Magnetics, vol. 48, no. 11, pp. 3100-3103, Nov. 2012. 